Discussiones Mathematicae

Note

\title{
MAXIMAL BUTTONINGS OF TREES
}

\author{
IAN SHORT ${ }^{1}$ \\ Department of Mathematics and Statistics \\ The Open University \\ Milton Keynes MKr $6 A A$ \\ United Kingdom \\ e-mail: ian.short@open.ac.uk
}

\begin{abstract}
A buttoning of a tree that has vertices $v_{1}, v_{2}, \ldots, v_{n}$ is a closed walk that starts at $v_{1}$ and travels along the shortest path in the tree to $v_{2}$, and then along the shortest path to $v_{3}$, and so forth, finishing with the shortest path from $v_{n}$ to $v_{1}$. Inspired by a problem about buttoning a shirt inefficiently, we determine the maximum length of buttonings of trees.
\end{abstract}

Keywords: centroid, graph metric, tree, walk, Wiener distance.

2010 Mathematics Subject Classification: Primary: 05C05, 05C38; Secondary: 05C85.

\section{REFERENCES}

[1] C.A. Barefoot, R.C. Entringer and L.A. Székely, Extremal values for ratios of distances in trees, Discrete Appl. Math. 80 (1997) 37-56. doi:10.1016/S0166-218X(97)00068-1

[2] A.A. Dobrynin, R. Entringer and I. Gutman, Wiener index of trees: theory and applications, Acta Appl. Math 66 (2001) 211-249. doi:10.1023/A:1010767517079

[3] L. Johns and T.C. Lee, S-distance in trees, in: Computing in the 90's (Kalamazoo, MI, 1989), Lecture Notes in Comput. Sci., 507, N.A. Sherwani, E. de Doncker and J.A. Kapenga (Ed(s)), (Springer, Berlin, 1991) 29-33. doi:10.1007/BFb0038469

[4] T. Lengyel, Some graph problems and the realizability of metrics by graphs, Congr. Numer. 78 (1990) 245-254.

Received 12 July 2012

Revised 10 December 2012

Accepted 10 December 2012

\footnotetext{
${ }^{1}$ The author thanks Jozef Širán̆ for helpful suggestions.
} 